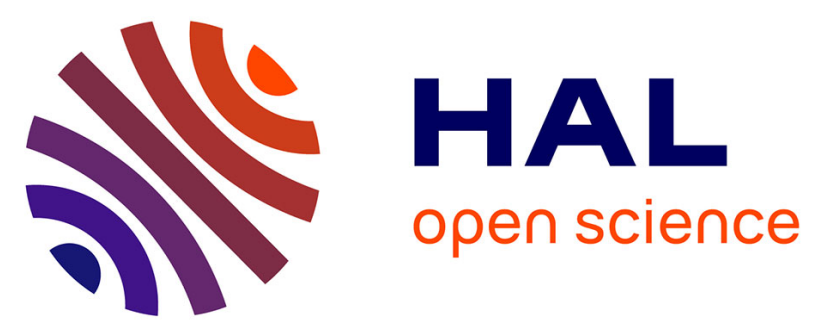

\title{
INTERPRETATION OF EXPERIMENTAL QUADRUPOLE SPLITTINGS OF IRON CONTAINING COMPLEXES USING MOLECULAR ORBITAL THEORY
}

\author{
A. Trautwein, R. Reschke, R. Zimmermann, I. Dezsi, F. Harris
}

\section{To cite this version:}

A. Trautwein, R. Reschke, R. Zimmermann, I. Dezsi, F. Harris. INTERPRETATION OF EXPERIMENTAL QUADRUPOLE SPLITTINGS OF IRON CONTAINING COMPLEXES USING MOLECULAR ORBITAL THEORY. Journal de Physique Colloques, 1974, 35 (C6), pp.C6-235-C6239. 10.1051/jphyscol:1974630 . jpa-00215787

\section{HAL Id: jpa-00215787 https://hal.science/jpa-00215787}

Submitted on 1 Jan 1974

HAL is a multi-disciplinary open access archive for the deposit and dissemination of scientific research documents, whether they are published or not. The documents may come from teaching and research institutions in France or abroad, or from public or private research centers.
L'archive ouverte pluridisciplinaire $\mathbf{H A L}$, est destinée au dépôt et à la diffusion de documents scientifiques de niveau recherche, publiés ou non, émanant des établissements d'enseignement et de recherche français ou étrangers, des laboratoires publics ou privés. 


\title{
INTERPRETATION OF EXPERIMENTAL QUADRUPOLE SPLITTINGS OF IRON CONTAINING COMPLEXES USING MOLECULAR ORBITAL THEORY (*)
}

\author{
A. TRAUTWEIN and R. RESCHKE
}

Angewandte Physik, Universität des Saarlandes, 66 Saarbrücken, W. Germany

\section{R. ZIMMERMANN}

Physikalisches Institut II, Universität Erlangen, 852 Erlangen, W. Germany

\section{DEZSI}

Central Research Institute for Physics, 1525 Budapest, Hungary

\section{F. E. HARRIS}

Department of Physics, University of Utah, Salt Lake City, Utah 84112, USA

\begin{abstract}
Résumé. - Nous étudions sur la base de calculs d'orbitales moléculaires plusieurs arrangements tridimensionnels des ligands autour du fer dans des complexes du fer-pentacyanure, dans $\mathrm{FeOCl}$ et dans des hèmes désoxygénés. Nous calculons les tenseurs de gradient de champ électrique (GCE) pour les diverses structures moléculaires étudiées et nous en déduisons les éclatements quadrupolaires, le paramètre d'asymétrie et les orientations de la composante $V_{z z}$ du GCE dont les valeurs sont comparées aux données expérimentales.
\end{abstract}

\begin{abstract}
On the basis of molecular orbital calculations we study several three dimensional arrangements of ligands with respect to iron in iron-pentacyanide complexes, in $\mathrm{FeOCl}$, and in deoxygenated heme compounds. For the various molecular structures under study we derive electric field gradient (EFG) tensors, from which we calculate quadrupole splittings, asymmetry parameter, and orientations of the EFG component $V_{z z}$, which are compared with experimental data.
\end{abstract}

1. Quadrupole splitting and electric field gradient tensor. - Experimental quadrupole splittings, $\Delta E_{\mathrm{Q}}^{\exp }$ are compared with theoretical estimates of

$$
\Delta E_{\mathrm{Q}}^{\mathrm{calc}}=\frac{1}{2} e Q V_{z z}\left(1+\frac{1}{3} \eta^{2}\right)^{1 / 2} .
$$

The quantity $e$ represents the (positive) elementary charge, and the nuclear quadrupole moment $Q$ is taken to be $-0.21 \mathrm{~b}$ [1-4]. The main component of the Electric Field Gradient (EFG) tensor, $V_{z z}$, being defined by $\left|V_{z z}\right| \geqslant\left|V_{y y}\right| \geqslant\left|V_{x x}\right|$ and the asymmetry parameter $\eta=\frac{\left|V_{x x}-V_{y y}\right|}{\left|V_{z z}\right|}$, result from diagonalizing the (EFG) tensor $V_{p q}(p, q=x, y, z)$. The aim of the present work is to derive $V_{p q}$ from the calculated

(*) Supported in part by Stiftung Volkswagenwerk, in part by the European Molecular Biology Organization, in part by an award from the Biomedical Sciences Support Grant at the University of Utah, in part by the Deutsche Forschungsgemeinschaft, and in part by the National Science Foundation. electronic structure of several iron containing complexes.

Many-electron molecular orbital (MO) wave functions are obtained by theoretical approaches as described elsewhere [1]. The matrix elements of the EFG tensor components $V_{p q}$ for two many-electron states $\mid l^{\prime}>$ and $\mid l>$ follow from [5] :

$$
\begin{aligned}
& \left.\left.<1^{\prime}\left|V_{p q}\right| 1\right\rangle=\sum_{h^{\prime}, h} C_{\left(I^{\prime}\right)\left(h^{\prime} h\right)}<\psi_{h^{\prime}}\left|V_{p q}\right| \psi_{h}\right\rangle+ \\
& \left.\quad+\sum_{h^{\prime}, h^{\prime \prime}}\left(C_{\left(1^{\prime} 1\right)\left(h^{\prime} h^{\prime \prime}\right.}\right)+C_{\left(1^{\prime}\right)\left(h^{\prime \prime} h^{\prime}\right)}\right)<\psi_{h^{\prime}}\left|V_{p q}\right| \psi_{h^{\prime \prime}}> \\
& \quad+\sum_{h^{\prime \prime}, h^{\prime \prime \prime}} C_{\left(\left(^{\prime}\right)\left(h^{\prime \prime} h^{\prime \prime \prime}\right)\right.}\left\langle\psi_{h^{\prime \prime}}\left|V_{p q}\right| \psi_{h^{\prime \prime}}>;\right.
\end{aligned}
$$

where the states $|\psi\rangle$ are atomic orbitals (AO's), the coefficients $C$ are their corresponding bond order matrix elements, the indices $h, h^{\prime}$ stand for Fe AO's, and $h^{\prime \prime}, h^{\prime \prime \prime}$ for ligand AO's, respectively. The matrix elements $\left\langle\psi_{h^{\prime}}\left|V_{p q}\right| \psi_{h^{\prime \prime}}\right\rangle$ are cross-terms between iron AO's and ligand AO's and can be transformed 
by introducing a completeness relation of orthogonal terms $\left|\psi_{h}^{-}\right\rangle$, which contain the iron $\mathrm{AO}$ 's $\left|\psi_{h^{\prime}}\right\rangle$, into

$$
\begin{aligned}
<\psi_{h^{\prime}}\left|V_{p q}\right| \psi_{h^{\prime \prime}} & > \\
= & \sum_{h}<\psi_{h^{\prime}}\left|V_{p q}\right| \psi_{h}^{-}><\psi_{h}^{-} \mid \psi_{h^{\prime \prime}}>.
\end{aligned}
$$

Since $V_{p q}$ does not lead out of the subspace of $\left|\psi_{h^{\prime}}\right\rangle$, the summation can be restricted to iron orbitals and we get :

$$
\left.<\psi_{h^{\prime}}\left|V_{p q}\right| \psi_{h^{\prime \prime}}\right\rangle=\sum_{h}<\psi_{h^{\prime}}\left|V_{p q}\right| \psi_{h}>S_{h h^{\prime \prime}},
$$

with $S_{h h^{\prime \prime}}$ representing overlap integrals between iron AO's $\psi_{h}$ and ligand AO's $\psi_{h^{\prime \prime}}$. With the use of eq. (2) and (3) we distinguish two parts of the tensor $V_{p q^{\prime}}$ (i) the so-called valence contribution

$$
\begin{gathered}
\left\langle 1^{\prime}\left|V_{p q}^{\mathrm{val}}\right| 1\right\rangle=\sum_{h^{\prime}, h}\left[C_{\left(\mathrm{I}^{\prime}\right)\left(h^{\prime} h\right)}+\right. \\
\left.+\sum_{h^{\prime \prime}}\left(C_{\left(1^{\prime}\right)\left(h^{\prime} h^{\prime \prime}\right)}+C_{\left(1^{\prime}\right)\left(h^{\prime \prime} h^{\prime}\right)}\right) S_{h h^{\prime \prime}}\right]<\psi_{h^{\prime}}\left|V_{p q}\right| \psi_{h}>,
\end{gathered}
$$

and (ii) the so-called lattice contribution

$$
\left\langle\mathrm{l}^{\prime}\left|V_{p q}^{\mathrm{lat}}\right| 1\right\rangle=\sum_{h^{\prime \prime}, h^{\prime \prime \prime}} C_{\left(1^{\prime} 1\right)\left(h^{\prime \prime} h^{\prime \prime \prime}\right)}<\psi_{h^{\prime \prime}}\left|V_{p q}\right| \psi_{h^{\prime \prime \prime}}>\text {. }
$$

Assuming the ligand charges $q_{a}$ to be localized at lattice points $\left(R_{x a}, R_{y a}, R_{z a}\right)$ we approximate $V_{p q}^{\text {lat }}$ of eq. (5) by

$$
\begin{aligned}
& \left\langle 1^{\prime}\left|V_{p q}^{\text {lat }}\right| 1>=\right. \\
& \quad=\left(1-\gamma_{\infty}\right) \sum_{a} q_{a}\left(3 R_{p a} R_{q a}-\delta_{p q} R_{a}^{2}\right) / R_{a}^{5},
\end{aligned}
$$

where $q_{a}$ and $\left(R_{x a}, R_{y a}, R_{z a}\right)$ are the charge and the cartesian coordinates of the ath ligand, and $\left(1-\gamma_{\infty}\right)$ represents the Sternheimer antishielding correction: $\left(1-\gamma_{\infty}\right)=10.1$. From MO calculations the information concerning $C_{\left(1^{\prime}\right)\left(h^{\prime} h\right)}, C_{\left(1^{\prime}\right)\left(h^{\prime} h^{\prime \prime}\right)}, C_{\left(I^{\prime}\right)\left(h^{\prime} h^{\prime}\right)}$, and $S_{h h^{\prime \prime}}$ is available. For the evaluation of $V_{p q}$ from eq. (4) and (6) it remains therefore to derive the matrix elements $<\psi_{h^{\prime}}\left|V_{p q}\right| \psi_{h}>$ from

$$
\begin{aligned}
<\psi_{h^{\prime}}\left|V_{p q}\right| \psi_{h}>= & \\
=<\|\mathrm{EFG}\|> & e(1-R)>r^{-3}>\times \\
& \times<\psi_{h^{\prime}}\left|1_{p q}\right| \psi_{h}>.
\end{aligned}
$$

In eq. (7) the reduced matrix element $\langle\|\mathrm{EFG}\|>$ takes the value $2 / 7$ for $d$ electrons, $6 / 5$ for $p$ electrons, and 0 for $s$ electrons. The quantity $e$ represents the (positive) elementary charge, and $\left\langle r^{-3}\right\rangle$ is the radial factor resulting from taking the expectation value of $\left(3 z^{2}-r^{2}\right) / r^{5}$. The $\left\langle r^{-3}\right\rangle_{3 \mathrm{~d}}$ are taken from estimates [6] based on Clementi's [7] atomic Hartree-Fock wavefunctions : 4.49 a. $\mathrm{u}$. for $\mathrm{Fe}$ configuration $3 \mathrm{~d}^{7}$, 5.09 a. u. for $3 \mathrm{~d}^{6}$, and 5.73 a. u. for $3 \mathrm{~d}^{5}$. The actual value of $\left\langle r^{-3}\right\rangle_{3 d}$ is determined for each compound from its calculated $\mathrm{Fe} 3 \mathrm{~d}$ orbital occupancy by interpolation between the foregoing values. The Sternheimer shielding correction is taken as $(1-R)=0.68$. For Fe $4 \mathrm{p}$ electrons the quantity $(1-R)_{4 \mathrm{p}}\left\langle r^{-3}\right\rangle_{4 \mathrm{p}}$ is taken to be $\frac{1}{3}$ of the corresponding quantity for the $3 \mathrm{~d}$ electrons $[3,8]$. Finally the single-electron operator $l_{p q}$ is given by

$$
1_{p q}=\frac{1}{2}\left(1_{p} 1_{q}+1_{q} 1_{p}\right)-\frac{1}{3} 1(1+1) \delta_{p q} .
$$

Thus the problem of calculating $\Delta E_{\mathrm{Q}}, \eta$ and the orientation of $V_{z z}$ is solved straight-forward by diagonalizing the tensor $V_{p q}$ and using eq. (1).

2. Temperature independent quadrupole splittings. The compounds presently under study are the diamagnetic clusters $\mathrm{Fe}(\mathrm{CN})_{5} \mathrm{NOC}_{6} \mathrm{H}_{5}^{-3}, \mathrm{Fe}(\mathrm{CN})_{5} \mathrm{NO}_{2}^{-4}$, $\mathrm{Fe}(\mathrm{CN})_{5} \mathrm{H}_{2} \mathrm{O}^{-3}, \mathrm{Fe}(\mathrm{CN})_{5} \mathrm{NH}_{3}^{-3}$, and the paramagnetic $\left(S=\frac{5}{2}\right)$ cluster $\mathrm{FeO}_{4} \mathrm{Cl}_{2}^{-7}$. Since the experimental quadrupole splittings of these compounds are temperature independent over a wide temperature range, we feel justified in limiting our MO calculations to selfconsistent-field studies which ignore the effect of lowlying excited electronic states. This has the simple consequence that we are concerned in eq. (2) only with diagonal matrix elements : $\left\langle 1\left|V_{p q}\right| 1\right\rangle$.

The molecular geometrics for which calculations were made are described in Table I. In Table II we give calculated electronic configurations and we compare $\Delta E_{\mathrm{Q}}^{\exp }$ with $\Delta E_{\mathrm{Q}}^{\mathrm{calc}}$. For compounds I to $\mathrm{V}$ we find good agreement between experimental and calculated quadrupole splittings. Since compound $\mathrm{V}(\mathrm{FeOCl})$ was investigated in single-crystalline from [14] we have the advantage to compare additional parameters :

$$
\begin{gathered}
\eta^{\exp }=0.32 \pm 0.03 \text { and } \eta^{\text {calc }}=0.23 \\
V_{z z}^{\text {exp }}<0 \text { and } V_{z z}^{\text {calc }}<0, \quad V_{z z}^{\text {exp }} / / V_{z z}^{\text {calc }} .
\end{gathered}
$$

Compounds VI and VII are identical, respectively, to compounds I and II, except that in VI and VII the non-axial ligands $\left(\mathrm{C}_{6} \mathrm{H}_{5}^{-}\right.$and $\left.\mathrm{NO}_{2}^{-}\right)$have been rotated relative to their position in $\mathrm{I}$ and II. Our results show that this rotation has a substantial effect upon the $\mathrm{Fe} 3 \mathrm{~d}$ charge density, and that the calculated quadrupole splittings have moved away from their corresponding experimental values. We therefore conclude that the orientation of $\left(\mathrm{C}_{6} \mathrm{H}_{5}^{-}\right.$and $\left.\mathrm{NO}_{2}^{-}\right)$relative to the ironpentacyanide complex are described better by compounds I and II than by VI and VII.

3. Temperature dependent quadrupole splittings. In deoxygenated myoglobin (MO) or hemoglobin (Hb) are concerned with electronic states

$$
11>=\left|\Gamma, \gamma, S, \gamma_{\mathrm{s}}\right\rangle
$$

which are energetically close by, and which are characterized by irreducible representations $\Gamma$ and by total spin $S=2$. All irreducible representations of the regarded symmetry group $C_{2 v}$ (Fig. 1) are one-dimen- 


\section{TABLE I}

Geometries used for iron-pentacyanide complexes and for $\mathrm{FeOCl}$. Geometry for $\mathrm{Fe}(\mathrm{CN})_{5}^{-3}$ based on $\mathrm{Na}_{2} \mathrm{Fe}(\mathrm{CN})_{5} \mathrm{NO} . \mathrm{H}_{2} \mathrm{O}$ (see ref. [1]). Symmetry axis of $\mathrm{Fe}(\mathrm{CN})_{5}^{-3}$ taken in $z$ direction. Geometry of 6 th ligand in cartesian coordinate $(\AA)$ relative to $\mathrm{Fe}$.

I. $\mathrm{Fe}(\mathrm{CN})_{5} \mathrm{NOC}_{6} \mathrm{H}_{5}^{-3} . \mathrm{N}:(0,0,1.63) ; 0:(0,0,2.42)$;

$\mathrm{C}_{1}:(-0.986,0,2.616) ; \mathrm{C}_{2}:(-1.476,0.49,3.106)$;

$\mathrm{C}_{3}:(-1.476,-0.49,3.106) ; \mathrm{C}_{4}:(-2.457,0.49,0.087)$;

$\mathrm{C}_{5}:(-2.457,-0.49,4.087) ; \mathrm{C}_{6}:(-2.947,0,4.577)$;

$\mathrm{H}_{1}:(-1.476,2.06,3.106) ; \mathrm{H}_{2}:(-1.476,-2.06,3.106)$;

$\mathrm{H}_{3}:(-2.457,2.06,4.087) ; \mathrm{H}_{4}:(-2.457,-2.06,4.087)$;

$\mathrm{H}_{\mathrm{s}}:(-4.046,0,5.676)$.

Coordinates of benzol (ref. 9). Fe-N and $\mathrm{N}-\mathrm{O}$ distance same as in $\mathrm{Fe}(\mathrm{CN})_{5} \mathrm{NO}^{-2}$. N-C distance in $\mathrm{NOC}_{6} \mathrm{H}_{5}$ from compounds like $\mathrm{C}_{6} \mathrm{H}_{4} \mathrm{~N}_{2} \mathrm{O}_{4}$ (ref. [9]).

II. $\mathrm{Fe}(\mathrm{CN})_{5} \mathrm{NO}_{2}^{-4} \cdot \mathrm{O}_{1}:(0.742,0.742,2.519)$;

$\mathrm{O}_{2}:(-0.742,-0.742,2.519) ; \mathrm{N}:(0,0,1.960)$.

Coordinates of $\mathrm{NO}_{2}^{-}$from compounds containing $\mathrm{NO}_{2}$ (ref. [9]). $\mathrm{Fe}-\mathrm{N}$ distance from $\mathrm{Ag}\left[\mathrm{Co}\left(\mathrm{NO}_{2}\right)_{4}\left(\mathrm{NH}_{3}\right)_{2}\right]$ (ref. [9]).

III. $\mathrm{Fe}(\mathrm{CN})_{5} \mathrm{H}_{2} \mathrm{O}^{-3} .0:\left(0,0,2.09 ; \mathrm{H}_{1}:(0,0.8,2.618)\right.$;

$\mathrm{H}_{2}:(0,-0.8,2.618)$.

Coordinates of $\mathrm{H}_{2} \mathrm{O}$ (ref. [9]). $\mathrm{Fe}-\mathrm{O}$ distance from $\mathrm{FeCl}_{2}, 4 \mathrm{H}_{2} \mathrm{O}$ (ref. [10]).

IV. $\mathrm{Fe}(\mathrm{CN})_{5} \mathrm{NH}_{3}^{-3} \cdot \mathrm{N}:(0,0,1.96) ; \mathrm{H}_{1}:(0.955,0,2.289)$;

$H_{3}:(-0.477,0.827,2.289) ; \mathrm{H}_{3}:(-0.477,-0.827,2.289)$.

$\mathrm{N}-\mathrm{H}$ distance from $\mathrm{NH}_{3}$ (ref. [11]). $\mathrm{NH}_{3}$ angles same as those for $\mathrm{CH}_{3}$ in $\mathrm{CH}_{3} \mathrm{CH}_{2} \mathrm{Br}$ (ref. [9]). Fe- $\mathrm{N}$ distance from Co-N compounds (ref. [9]).

V. FeOCl. $\mathrm{Fe}:(0,0,0) ; \mathrm{Cl}_{1}:(1.651,-1.651,0) ; \mathrm{Cl}_{2}:(-1.651,-1.651,0) ; \mathrm{O}_{1}:(1.651,1.315,0) ; \mathrm{O}_{2}:$ $(-1.651,1.315,0) ; \mathrm{O}_{3}:(0,0.575,1.89) ; \mathrm{O}_{4}:(0,0.575,-1.89)$.

Coordinates taken from (ref. [12]).

VI. $\mathrm{Fe}(\mathrm{CN})_{5} \mathrm{NOC}_{6} \mathrm{H}_{5}^{-3}$. Same as compound $\mathrm{I}$ but with $\mathrm{C}_{6} \mathrm{H}_{5}^{-}$rotated by $90^{\circ}$ around the $\mathrm{N}-\mathrm{C}_{1}-\mathrm{C}_{6}-\mathrm{H}_{5}$ axis.

VII. $\mathrm{Fe}(\mathrm{CN})_{5} \mathrm{NO}_{2}^{-4}$. Same as compond II but with $\mathrm{NO}_{2}^{-}$rotated by $45^{\circ}$ around the $z$ axis.

\section{TABLE II}

Calculated electronic configurations $3 \mathrm{~d}^{\mathrm{m}} 4 \mathrm{~s}^{\mathrm{n}} 4 \mathrm{p}^{\circ}$ and experimental and theoretical quadrupole splittings for the complexes specified in Table $\mathrm{I} . \Delta E_{\mathrm{Q}}^{\mathrm{calc}}$ is calculated as described in the text

\begin{tabular}{|c|c|c|c|c|c|c|c|}
\hline Compound & I & II & III & IV & V & VI & VII \\
\hline- & - & - & - & - & - & - & - \\
\hline $\mathrm{m}, \mathrm{n}, \mathrm{o}$ & $6.89,0.15,0.74$ & $6.88,0.15,0.73$ & $6.99,0.15,0.65$ & $6.98,0.14,0.66$ & $5.67,0.19,0.70$ & $6.7,0.13,0.69$ & $6.88,0.15,0.73$ \\
\hline $\begin{array}{l}E_{Q}^{\exp } \\
(\mathrm{mm} / \mathrm{s})\end{array}$ & $1.32 \pm 0.03(a)$ & $0.85 \pm 0.03(a)$ & $0.75 \pm 0.03(a)$ & $0.65 \pm 0.03(a)$ & $0.916 \pm 0.001\left(^{b}\right)$ & & \\
\hline $\begin{array}{l}E_{Q}^{\text {calc }} \\
(\mathrm{mm} / \mathrm{s})\end{array}$ & 1.24 & 0.71 & 0.68 & 0.64 & 0.828 & 2.55 & 1.11 \\
\hline
\end{tabular}

(a) Taken from reference [13].

$\left({ }^{b}\right)$ Taken from reference [14]. 


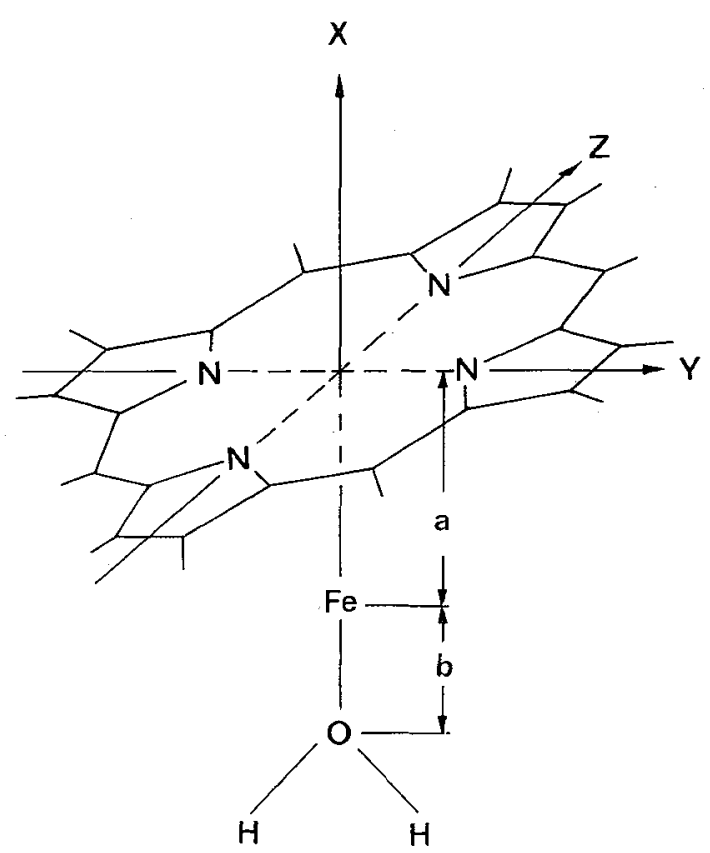

Fig. 1. - Stereostructural models for $\mathrm{Mb}$ or $\mathrm{Hb}:$ (I) $a=0.4 \AA$, $b=2.09 \AA$; (II) $a=0.4 \AA, b=2.34 \AA$; (III) $a=0.8 \AA$ $b=2.34 \AA$.

sional and thus $\gamma$ can be omitted. The five-fold spin degeneracy of each state $\Gamma$ is lifted by spin-orbit interaction, $H_{\text {s.o }}=-\lambda L . S$, with the coupling constant $\lambda$ being related to the free ion value, $\lambda_{0}=103 \mathrm{~cm}^{-1}$, by a reduction factor $\alpha^{2}: \lambda=\alpha^{2} \lambda_{0}$. The eigenvectors $\left|e_{\alpha}\right\rangle$ of this problem, having energies $E_{\alpha}$, are certain linear combinations of the base vectors $\left|\Gamma, S, \gamma_{S}\right\rangle$ :

$$
\left|e_{\alpha}>=\sum_{\Gamma, \gamma_{\mathrm{s}}} C_{\Gamma, \gamma_{\mathrm{s}}}^{\alpha}\right| \Gamma, S, \gamma_{\mathrm{s}}>
$$

Since we are interested in quadrupole splittings we calculate for each state $\mid e_{\alpha}>$ its relevant EFG tensor :

$$
V_{p q}^{\alpha}=\left\langle e_{\alpha}\left|V_{p q}\right| e_{\alpha}\right\rangle \text {. }
$$

By use of eq. (9) and

$$
\begin{aligned}
\left.<1^{\prime}\left|V_{p q}\right| 1\right\rangle & =<\Gamma^{\prime}, \gamma_{s}^{\prime}\left|V_{p q}\right| \Gamma, \gamma_{\mathrm{s}}> \\
& =\left\langle\Gamma^{\prime}\left|V_{p q}\right| \Gamma>\delta_{\gamma_{s} \gamma_{\mathrm{s}}}^{\prime}\right.
\end{aligned}
$$

$V_{p q}^{\alpha}$ can be written as a sum of matrix elements $\left\langle 1^{\prime}\left|V_{p q}\right| 1\right\rangle$, which have been defined in section 1 . In order to evaluate the temperature dependence of the EFG one must average the components $V_{p q}^{\alpha}$ of the individual substates $\mid e_{\alpha}>$ according to Boltzmannstatistics :

$$
<V_{p q}>_{r}=\sum_{\alpha} V_{p q}^{\alpha} \exp \left(-E_{\alpha} / k T\right) / \sum_{\alpha} \exp \left(-E_{\alpha} / k T\right)
$$

Diagonalization of $\left\langle V_{p q}\right\rangle_{T}+V_{p q}^{\text {lat }}$ leads to $V_{z z}(T)$, to $\eta(T)$, to the orientation of $V_{z z}(T)$, and finally through eq. (1) to $\Delta E_{\mathrm{Q}}(T)$.
For each of the three models of figure 1 we then calculate the above parameters. The final $\Delta E_{\mathrm{Q}}(T)$ - and $\eta(t)$-curves together with their corresponding energies $E\left({ }^{5} \mathrm{~A}_{2}\right), E\left({ }^{5} \mathrm{~B}_{1}\right)$ and $E\left({ }^{5} \mathrm{~B}_{2}\right)$ [15] and with experimental $\Delta E_{\mathrm{Q}}(T)$-data for $\mathrm{Mb}$ and $\mathrm{Hb}$ are shown in figure 2 for model I. For models II and III no $\Delta E_{\mathrm{Q}}$-fit curve was

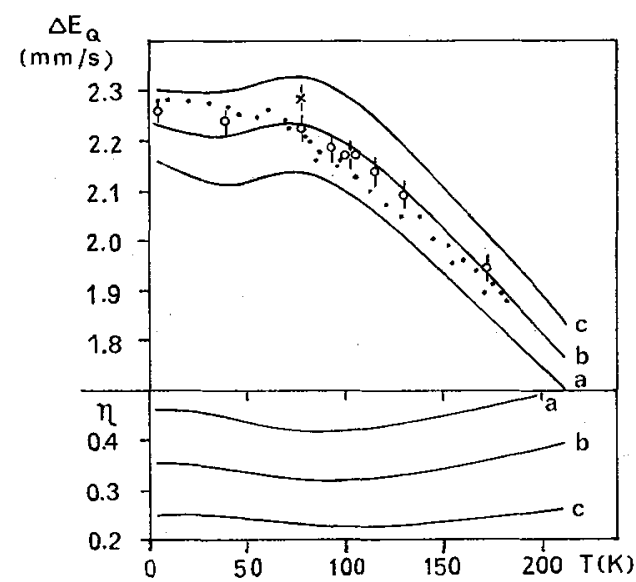

FIG. 2. - Temperature dependent quadrupole splittings, $E_{\mathrm{Q}}(T)$, and asymmetry parameters, $(T)$, for model $I$ of figure 1 . $\lambda=-75 \mathrm{~cm}^{-1}$. Experimental $E_{\mathrm{Q}}(T)$ data for frozen $\mathrm{Mb}$ solution (ref. [19]) are indicated by closed circles, for a $\mathrm{Mb}$ single crystal (ref. [17]) by «X» and errors bars, and for frozen $\mathrm{Hb}$ (rat, ph 10) solution (ref. [20]) by open circles and error bars. Energies for ${ }^{5} \mathrm{~B}_{2},{ }^{5} \mathrm{~B}_{1}$, and ${ }^{5} \mathrm{~A}_{2}$ in $\mathrm{cm}^{-1}$ corresponding to $E_{\mathrm{Q}}(T)$ - and $(T)$ - curves are : a) $\left.0,150,150 ; b\right) 0,150,175$; c) $0,150,200$.

obtained. A low lying ${ }^{1} \mathrm{~A}_{1}$ state has negligible influence on $\Delta E_{\mathrm{Q}}(T)$ and $\eta(T)$, and a low lying ${ }^{3} \mathrm{E}$ state is ruled out by the fact that a low-energy term scheme including intermediate spin states does not correspond to the experimental susceptibility data, $\chi(T)$, for $\mathrm{Mb}$ of Nakano et al. [16], whereas the term scheme related to curve $b$, figure 2 , nicely fits the experimental $\chi(T)$ data. Further, we find from our calculations $V_{z z}>0$ and $V_{z z}$ being oriented along the heme axis $y$ (Fig. 2), in reasonable agreement with our recent findings from Mössbauer investigation of $\mathrm{Mb}$ single crystals at $77 \mathrm{~K}$ [17]. A most recent computational analysis of our former Mb single crystal Mössbauer data by Y. Maeda (private communication, 1974) indicates that an orientation of $V_{z z}$ parallel to the hemeplane is consistent also with an $\eta$-parameter in the range $0 \leqslant \eta \leqslant 0.7$.

4. Conclusion. - All compounds under study here exhibit covalent bonding to varying degrees and therefore may appropriately be handled by methods based on molecular-orbital theory rather than by crystal-field methods. Still, the present MO interpretation of experimental quadrupole splittings of the various complexes is approximative in the sense that the clusters which are specified by Table I and figure 1 are models only for the real compounds, and further, that the MO procedure itself is approximative to the extend described in 
ref. [1]. These simplifications, however, are believed to be secondary for the present attempt to derive a gross description of the structural situation around the iron. From the present work we therefore conclude that the MO interpretation of experimental quadrupole split- tings consistently agrees with the three dimensional structures of compounds $I$ to $V$ in Table $I$, and also agrees with the assumption that the heme iron in $\mathrm{Mb}$ and $\mathrm{Hb}$ is pentacoordinated and significantly out of the hemeplane (by $\approx 0.4 \AA$ ).

\section{References}

[1] Trautwein, A. and Harris, F. E., Theor. Chim. Acta 30 (1973) 45.

[2] Trautwein, A., Kreber, E., Gonser, U. and Harris, F. E., J. Phys. Chem. Solids (in press).

[3] Trautwein, A. and Harris, F. E., Phys. Rev. B 7 (1973) 4755.

[4] Sharma, R. R., Phys. Rev. Lett. 26 (1971) 563.

[5] Trautwein, A., Zimmermann, R. and Harris, F. E., Theor. Chim. Acta (in press).

[6] Weissbluth, M. and Maling, J, E., J. Chem. Phys. 47 (1967) 4166.

[7] Clementi, E., I. B. M. J. Res. Develop. Suppl. 9 (1965) 2.

[8] De Vries, J. L. K. F., KreiJzers, C. P. and DE Boer, F., Inorgan. Chem. 11 (1972) 1343.

[9] Tables of Interatomic Distances and Configurations in Molecules and Ions, L. E. Sutton, Ed. (London, Chem. Soc.) 1958.

[10] Penford, B. R, and Grigor, J. H., Acta Cryst. 12 (1959) 850.

[11] Pauling, L., Nature of Chem. Bonds, p. 226.

[12] Lind, M. D., Acta Cryst. B 26 (1970) 1058.
[13] Dezsi, I., Molnar, B., Srolay, T. and Iaszberesyi, I., Chem. Phys. Lett. 18 (1973) 598 ;

Dezsi, I., Molnar, B. and Srolay, T., Chem. Phys. Lett. (to be published).

[14] Grant, R. W., Wiedersich, H., Housely, R. M. and EsPINosA, G. P., Phys. Rev. B 3 (1971) 678.

[15] The irreducible representations ${ }^{5} \mathbf{A}_{2},{ }^{5} \mathbf{B}_{1}$ and ${ }^{5} \mathbf{B}_{2}$ correspond to the axis-convention of figure 1 and to the symmetry group $\mathrm{C}_{2 \mathrm{v}}$.

[16] Nakano, N., Otsuka, J. and Tasak, A., Biochem. et Biophys. Acta 236 (1971) 222.

[17] Trautwein, A., Maeda, Y., Gonser, U., Parak, F. and FoRMANEK, H., in « Proceedings of the 5 th International Conference in Mössbauer Spectroscopy", Bratislava, CSSR, Sept. 1973.

Gonser, U., Maeda, Y., Trautwein, A., Parak, F. and FoRMANEK, H., Z. Naturforsch. 29 b (1974) 241.

[18] Eicher, H., Parak, F., Bade, D., Tejada, X. and Kalvius, G. M., in J. Physique Collq. 35 (1974) C 6.

[19] Excher, H. and Trautwein, A., J. Chem. Phys. 50 (1969) 2540. 